\title{
Jovens e construções subjetivas: identidade e valores interagem na hipertextualidade
}

\author{
Mirian Paura Sabrosa Zippin Grinspun ${ }^{1}$ \\ mzippin@yahoo.com.br
}

Patricia Manescky D. Costa ${ }^{2}$
patriciaduarte2009@gmail.com

Resumo

A pesquisa apresenta as análises da dissertação "Os jovens e o mundo virtu@l: as artimanhas dos valores nos ch@ts da internet", têm como objetivo identificar valores construídos pelos jovens na comunicação cibernética e suas implicações na construção identitária individual e coletiva, explora concepções conceituais a respeito da categoria juventude a partir do saber elaborado nas relações "comunicacionais experienciadas" no ciberespaço. Explora relações com a aprendizagem escolar e informal das salas de bate papo. Abordagem qualitativa, com pesquisa descritiva e exploratória, constituída por instrumentos com técnicas múltiplas, indo da formalidade dos questionários à informalidade das salas de chats. A análise e interpretação dos dados

\footnotetext{
${ }^{1}$ Professora doutora titular da Universidade do Estado do Rio de Janeiro (UERJ), atuando em pesquisas e orientações de mestres e doutores no Programa de Pós-Graduação em Educação (PROPED) da UERJ. Coordena o Grupo de Pesquisa Jovens, Valores eSubjetividades (Nupejovem). Doutora em Filosofia pela Universidade Gama Filho, mestre em Estudos Avançados em Educação pela Fundação Getúlio Vargas, especialista em Orientação Educacional, Supervisão Escolar e Administração Escolar pela UERJ.

${ }^{2}$ Professora doutora em Educação pelo PROPED/UERJ. Pesquisadora do Grupo Pesquisa Extensão Universitária: políticas e práticas (FEBF/UERJ). Mestre em Educação pelo PROPED/ UERJ. Especialista em Administração, Orientação Educacional e Docência do Ensino Superior. Graduada em Pedagogia pela Universidade Federal do Rio de Janeiro (UFRJ). Coordenadora do Instituto Superior de Educação / ISE e Coordenadora do Curso de Pedagogia das Faculdades Gama e Souza. Professora do Centro Universitário da Cidade (Univercidade), Faculdades Dom Bosco (AEDB) e Fundação de Apoio à Escola Técnica do Estado do Rio de Janeiro (FAETEC).
}

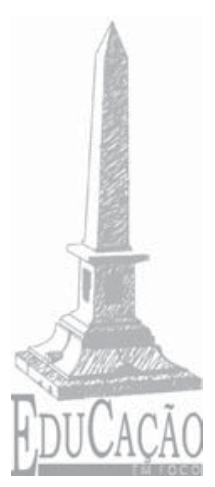

13 
norteiam-se pelo método analítico e dialético, permitindo constante formulação de hipóteses. O referencial teórico entremeia esclarecendo aspectos da sociologia e psicologia da juventude, axiologia dos valores e sentido/significado da tecnologia. O ciberespaço ressignifica espaços do ensinar/aprender nas múltiplas facetas que o sujeito, hoje, se compõe/constrói.

Palavras-chave: Jovens; valores; subjetividade; identidade; cibercultura.

A masmorra eletrônica [...] sem peso algum entregue à fantasia [...] e sempre na solidão tilintante do éter.

Marion Fugléwcz ${ }^{3}$

Os valores estão presentes na sociedade com significados dispostos "entrelinhas", na dimensão entre as ações e a construção do pensamento.

$\mathrm{Na}$ pesquisa os jovens demonstraram eleger valores que permeiam suas vidas cotidianas de forma que não se pode negar a presença do entrelace subjetivo bem como o cultural, o social, o político, o econômico e o histórico, posto no contexto em que está acostumado a lidar.

Incrivelmente podemos discutir a representação de valores que brotam da linguagem simbólica dos chats. Porém, se pode também discutir os valores que já estão bem representados entre os jovens fora das salas de chats, ou seja, as convenções que traçam a partir de comportamentos instituídos nos diferentes grupos. Diante disso, também se pode perceber que os valores parecem ser os mesmos para a maioria. Assim relatam os dados de nossa pesquisa, quando, por exemplo, se convenciona que todos devem gostar de cinema ou que a maioria considera a amizade o maior valor. Há um sentido dúbio na tentativa de encontrar os valores mais presentes

${ }^{3}$ FUGLÉWCZ, 2001, p. 9.

Ano 12 - n. 14 - dezembro 2009 - p. 13-39 
nos jovens. Enquanto teóricos discutem que há características flutuantes entre os jovens, e que suas representações em valores é bastante diferenciada, gerando entre eles tribos ou neotribos (MAFFESOLI, 2000); identifica-se, por outro lado, valores semelhantes como a amizade e a escola. Então, pode-se intervir que além de interesses diferentes que identificam e representam as neotribos, os grupos de jovens também apresentam características semelhantes. É justamente desse caleidoscópio complexo de valores que os jovens constituem e saboreiam a transição de valores nas sociedades e nas culturas no contexto atual, indica Grinspun (2002).

Outras características surpreendem: identificamos a presença nos chats tanto de meninos quanto de meninas a partir da idade em que ocorre uma estabilidade específica para ambos os sexos, que vai de 14 aos 21 anos inclusive. Isso se pode inferir com relação ao interesse dos jovens pelo veículo de comunicação em determinada faixa etária? Seria um dado interessante a ser pesquisado, pois poderia constituir-se uma característica e um valor da própria faixa etária, como também do grupo que utiliza esse veículo de comunicação. Será que é um modismo ou um comportamento estabelecido pelos jovens que têm acesso à era tecnológica com maior facilidade, por exemplo, marcar hora para se encontrar no chat além do encontro presencial diário na escola?

Outro valor que se põe no inconsciente coletivo do senso comum é a troca de identidade no espaço virtual. Encontramos uma resposta totalmente contrária. O jovem se preocupa mais com a mudança da identidade como precaução aos perigos do veículo de comunicação ou para ser aceito no chat para conversar e se manter por dentro dos assuntos do que para experimentar a si próprio. Talvez essa seja mais uma das questões que mereçam relevância nos estudos, pois quantos jovens não se preocupam de estar expondo suas emoções no imediato das conversas de chat, sem perceber que podem desconhecer totalmente a pessoa que está do outro lado do computador. Ao mesmo tempo se deve considerar que muitos já formam amizades intensas com outros jovens que conhe-

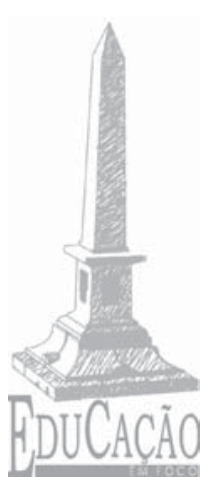


ceram na própria internet e travaram uma relação de confiança, nascendo uma amizade desprovida de interesses escusos, considerando inclusive já serem colegas no próprio cotidiano presencial. Mais uma vez a complexidade se faz presente, exigindo preciso olhar mais de perto, com maior exclusividade.

Os valores vão surgindo nas conversas e mostrando que estão presentes tanto os de posse particular como os da sociedade em que estão postos. Outro dado relevante é que muitos valores e interesses postos pelos jovens nos chats parecem ser valores que a própria sociedade tratou de identificar como sendo da juventude e identificador dos grupos. Entre esses valores, os tipos de símbolos na linguagem para dar representação a determinadas tribos, e outros também são considerados de todos, tais como as gírias mais comuns.

Na teoria conhecida como Psicologia Genética, do psicólogo suíço Jean Piaget, a inteligência não é inata, "mas a gênese da razão, da afetividade e da moral" (PADILHA, 1999) é feita progressivamente através de estágios sucessivos em que a criança organiza o pensamento e o julgamento. O saber é construído e não imposto de fora. Para Jean Piaget, o desenvolvimento moral é concomitante ao desenvolvimento lógico, com aspectos paralelos de um mesmo processo geral de adaptação. Existe uma reflexão consciente da prática passando por estágios, indo da moral heterônoma - que se constrói a partir da obediência - à moral autônoma - fundamentada na igualdade - baseando-se nas relações sociais. Em um primeiro momento a relação da criança com o adulto se estabelece na base da autoridade, em um segundo momento se estabelece na relação entre companheiro, num sistema de reciprocidade.

Como se pode observar, os valores estarão associados ao modo correto ou não, que o desenvolvimento da moral acontece no indivíduo. É durante o período da adolescência, em que é forte a afirmação da própria identidade, que os conflitos morais são ativos. Obedecer à autoridade do adulto não corresponde ao desenvolvimento do próprio "eu". Nesse movimento contrário, cresce a necessidade de liberdade e de coerência consigo mesmo, norteando o 
caminho de adaptação e autonomia. Esse exercício entre conflito e adaptação "favorece a capacidade de adaptação do indivíduo a uma sociedade em contínua mudança e conflito" (DÍAZAGUADO, 1996), como são hoje as sociedades industrializadas, sendo necessária uma educação baseada na resolução de problemas. Os valores ao mesmo tempo em que estão relacionados intimamente às formações do indivíduo, também são eleitos e emergentes da cultura e/ou sociedade a que cada indivíduo pertence.

Na teoria do psicólogo Lev Senyonovitch Vygotsky, a abordagem fundamenta-se na relação entre pensamento e linguagem, procurando possibilitar a descrição e a explicação das funções psicológicas superiores, incluindo a identificação dos mecanismos cerebrais subjacentes a uma determinada função, em que a influência dos mecanismos culturais são decisivos na natureza de cada pessoa. A cultura que fornecerá ao indivíduo os sistemas simbólicos de representação da realidade e, por meio deles, o universo de significações que permite construir uma ordenação, uma interpretação dos dados do mundo real. Nessa visão torna-se indispensável à construção de valores a vivência da escola no mundo social dos adolescentes. E é nessa visão que a construção dos valores pode ser flutuante, ao considerarmos a interação realizada nas salas de chat no ciberespaço.

A partir das duas teorias da aprendizagem, identifica-se que os valores estão presentes, porém a flutuação dos mesmos na interação socio-histórico-cultural será mais intensa. Assim, exigindo do indivíduo uma capacidade de plasticidade às mudanças tão presentes nas sociedades da informação hoje.

No estudo dos valores, encontramos autores com posturas diferentes, mas em um dado geral equiparam suas ideias pela própria constituição objetiva do que seja valor. Em dias como os das sociedades da informação, os valores estão implícitos nas vivencias relacionais informatizadas. A crise em que os jovens vivenciam hoje está posta nas condições e tipos de relações que vivenciam com os diversos campos da formação de um sujeito, ou seja, na

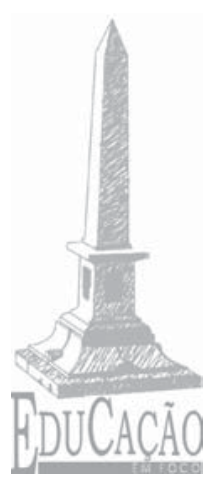


imbricada teia da vida cotidiana. Essa teia permeada de valores, ora explícitos, ora implícitos, orienta as condutas desses jovens.

As dúvidas sobre quais valores devem eleger para esse tipo de mundo hoje são questões que afligem nossos jovens em todas as dimensões de escolhas que devem estabelecer e orientar suas vidas. Ao mesmo tempo se deparam com valores do passado, do presente, os anunciados para o futuro e, ainda, aqueles em construção/desconstrução pela própria condição histórica do conhecimento com que o homem concebe suas formas de pensar e agir. Algumas questões são levantadas, tais como: Quais os valores que fundam as sociedades hoje? Como e a partir do que identificamos esses valores? E ainda se levantam questões pertinentes e específicas no que tange a presente pesquisa, tais como: "Quais os valores que os jovens veiculam nas salas de internet e até que ponto esses valores em interação com eles influem em suas vidas, e em suas identidades? Sabemos que a questão cultural desenha decisivamente o contexto dos valores, se observa que também evidencia novas posturas valorativas advindas de grupos principalmente quando se refere a jovens e seus contextos de formação identitária a partir da visão sociológica.

Nesta pesquisa, procuramos estudar um pouco mais a questão dos valores tanto na constituição teórica como na composição dessa categoria que emerge da fala dos jovens. Para tecer essa reflexão se traz o entrelace dos conceitos com os dados obtidos na pesquisa.

Para Chauí (1999), os juízos de valor são a avaliação sobre as coisas, pessoas, situações e são proferidos na moral, nas artes, na política, na religião. Eles avaliam coisas, pessoas, ações, experiências, acontecimentos, sentimentos, estado de espírito, intenções e decisões como bons ou maus, desejáveis ou indesejáveis. E o pensamento do homem é responsável por interpretar e avaliar as situações, atribuindo assim juízos de valor. Sob esse ponto de vista, o homem tem a capacidade de valorar sobre sua vida orientando-a sob a escolha eleita. Ao mesmo tempo em que vislumbra essa capacidade, já a esta realizando o tempo todo em seu cotidiano. Refle- 
tindo, podemos inferir que se os próprios jovens possuem essa capacidade de valorar, estão, assim, o tempo todo vivenciando valores nas salas dos chats.

Quando Henssen (1980) nos afirma que o valor não pode ser desligado da relação, pois no conceito de valor está incluído o da sua referência a um sujeito, seja ele, classificado por Henssen (1980), sujeito geral ou supra-individual e interindividual. Henssen (1980) usa o termo "trans-subjetivo" no sentido de transcendente, dentro de uma linha fenomenológica. Dessa forma, consideramos o homem situado, ou seja, aquele que está no mundo no agir/no fazer, na "concretude".

Nessa visão, os jovens estão realmente inseridos no mundo concreto quando nos referendamos do ponto de vista da utilização, manipulação dos aparatos tecnológicos e também com a própria desenvoltura que manuseia as complexas máquinas da "teleinformatização". As relações com a concreta aparelhagem da mídia interferem na relação valorativa com que os jovens se relacionam com as máquinas também. Esse dado nos indica que essa relação passa a ser intersubjetiva e transcendente quando se aporta das questões em que a relação passa do material para o subjetivo, para o pensamento, para as construções de signos. E isso compõe incessantemente as práticas realizadas nas salas de chats. A interação não se dá apenas no nível da operacionalização material do computador, mas se lança além, invadindo de forma a aguçar a área das percepções. Também envolve o movimento biológico de todo o organismo e chega à área psicológica e das emoções. Um misto de integração homem-máquina, transcendendo os limites do pensamento, das próprias posturas valorativas enquanto relação sem direcionamento, podendo assim referirmos ao visualizar as conversas nas salas de chat, a partir do momento em que se interage com o corpo que digita, a visão que lê, o pensamento que pergunta e responde, afirma e nega lógicas construídas em segundos de interatividade.

Já nos referimos diversas vezes a essa complexa relação aqui

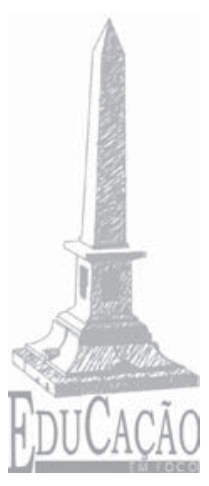


exposta, mas onde podemos pensar na construção do valor, em um ambiente de relação não presencial, mas que desenha explicitamente como se o fosse? A questão da virtualidade se impõe como dona de nossas ações/ interações das pessoas nesse espaço. Podemos ser o que quiser, imaginar o que quiser, fingir o que quiser, podemos criar para o bem ou para o mau, o que quiser criar no sentido de transfigurar a imagem de si tanto em nível físico como intelectual.

A formação de valores nesse contexto nos parece flutuante, assemelhando-se as características de conceituação da identidade dos jovens. Com isso, ainda se torna mais complexo definir valores a partir desse contexto. Porém, percebe-se que nos movimentos que ocorrem nas salas de chats referentes aos assuntos conduzidos, aos comportamentos expressos por meios de símbolos e às linguagens utilizadas, desenham modos de "estar" e "ser" no chat peculiares, mas também cheio de delimitações impostas pelos próprios jovens. Podemos assim dizer que alguns símbolos e seus significados, no que tange à percepção dessas regras virtuais, mas reais, demonstram que valores são estabelecidos, de forma muito clara, para se estar em uma sala de chat conseguindo desenvolver uma conversa com outra/outras pessoas. Não está escrito em nenhum lugar dentro das salas de chat, explicitamente, o que você pode ou não pode fazer, há uma sensação de "pode tudo", mas uma liberdade limitada pela intervenção/ integração do outro. Os próprios jovens admitem que algumas regras poderiam existir nos chats, inclusive citam algumas que deveriam ser criadas como: proibir pornografia; poder falar palavrão; delimitar a quantidade de pessoas nas salas; falar a verdade; proibir endereços e telefones; não haver conversa no reservado, dentre outras. Se referindo às regras, os jovens gostariam que fosse regra: "não zoar a conversa dos outros" e "nem invadir as conversas reservadas", além das outras questões que também tiveram expressiva votação. O que se observa aqui é que o jovem realiza escolhas e às vezes é muito duro até consigo mesmo. Apesar de não seguir muito as regras, ele admite que foge delas quando se sente acuado. Scheller (1997) ajuda a 
reflexão nesse contexto ao demonstrar, em sua classificação dos valores, a presença de valores éticos ou morais que, podemos dizer, estão sendo utilizados pelos jovens nessa questão, pois estão cambiando entre o justo e injusto.

Assim, essa classificação de Scheller (1997) se depara com outras práticas que os jovens relatam acontecer nos chats e que implicam valores como: a própria mudança de identidade não é uma característica generalizada, porém se apresenta no valor vivenciado dos valores lógicos ou intelectuais, indo da verdade à falsidade ou mesmo do certo ao duvidoso. Os jovens estão experimentando a mudança de identidade e isso vem das necessidades de conhecer e explorar o mundo em que vivem e a si próprios.

O valor lógico sugerido por Scheller (1997) ainda associa a função do conhecer, ter a posse do que é verdadeiro para alcançá-lo. E nessa questão também se levanta outro dado que complexifica a atribuição de valor realizada nas salas de chats, que se refere aos comportamentos emergentes da virtualidade vivida naquele momento. $\mathrm{O}$ imaginário se revela maior do que o valor do lógico. $\mathrm{O}$ ilógico e dialógico invadem esse tipo de ciberespaço permeando dúvidas e do inexistente-falso. Dessa forma, imediata o valor lógico que existia, segundo a classificação de Scheller (1997), passa a ser então do campo do valor ético, em que se desconsidera a relação e passa a introspecção de sua viagem virtual.

Também verificamos que os valores sensíveis não estão aí relacionados somente a uma esfera desse valor, ele perpassa os três campos como tal: os valores do agradável e do prazer em que se desfruta da virtualidade em situações prazerosas através do desenvolvimento de jogos; o próprio ato de "zoar" para os jovens tem um significado prazeroso, tanto que foi o item mais votado na questão; o fazer sexo virtual também se classifica aí; o próprio prazer da diversão "zoar" e "falar com os amigos", o "ouvir música" e "conversar sobre cinema" -itens mais votados nos assuntos preferidos. Isso revela o quanto as salas de chat estão vinculadas ao valor do agradável, os vitais e os de utilidade - que são os valores sensíveis.

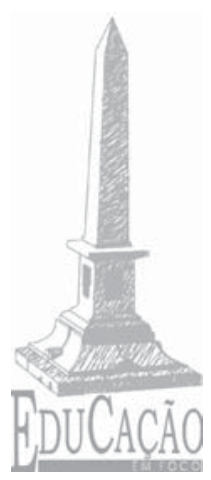

21 
Nessa análise, identificamos também o valor atribuído à escola como sendo um dos mais votados em seus assuntos. Diante dessa questão, podemos inferir que a escola tem um grau de importância na vida dos jovens e não é pequena, mas também seria interessante saber porque os jovens atribuem esse valor à escola. Na pesquisa não ficou muito claro, parece estar agregado ao valor da "amiza$\mathrm{de}^{\prime \prime}$, que vem acima de todos os demais. Isso porque, ao analisar as respostas do questionário que trata da relação do chat como campo de aprendizagem, observamos os jovens desinteressados da associação do ensino que poderia ser realizado nas salas de chat. Por outro lado, inferimos também que as representações que o jovem pode ter sobre o ensino e os conhecimentos podem estar vinculadas diretamente à formalidade com que as escolas trabalham seus conhecimentos conceituais em destaque e pouco trabalhem os conhecimentos "atitudinais" e "procedimentais" ${ }^{4}$, ou também à forma com que trabalham os conhecimentos, de modo geral, disciplinar, repletas de conteúdos "des-significados" de seus contextos. Para essa análise, seriam necessárias maiores discussões teóricas.

Percebemos nas observações que as salas de chats suscitam emoções múltiplas. Os jovens estão em constante mobilidade de sentimentos e emoções, indo da satisfação à irritação em curtos espaços de conversa. Isso também possibilita dizer que, no que tange a imprimir valores de maior grau ou intensidade, fica esvaziado de significação. Essa questão evidencia o que tantos estudos sobre o ciberespaço nos remetem: às implicações das vivencias momentâneas sem solidificação de uma base em que se possa fundamentar uma ideia ou um valor. Por outro lado, também devemos considerar o esvaziamento do pensamento enquanto materialidade, ou seja, lidar com o real - no sentido marxista do termo -, pois o virtual será respaldado pelo que o jovem se interessa, por "zoar" e "passar tempo".

Porém, os valores se transfiguram com a construção históricosocial, estão em constante mutação. Essa mutação de valores

${ }^{4}$ Os conceitos de conhecimento de Zabala (2000) identificam uma metodologia de trabalho diversificado, em que cada um dos tipos de conhecimento podem ser trabalhados para o alcance de uma melhor aprendizagem. 
intermediada pela virtualidade e pela interatividade é identificada nas salas de chat. Também identificando-se valores próprios desses ambientes, e a constituição será flutuante em decorrência dos frequentadores das salas de chat. Percebemos então que, além dos valores estarem colocados na interação entre os sujeitos e seus contextos - indivíduo + cultura + ciberespaço -, devemos considerar o que "a pessoa percebe o que vale para ela enquanto ser singular que difere dos demais, o seu entendimento a respeito dos valores grupais e dos princípios morais" (ANTUNES, 1999, p. 2) que poderão tornarem-se mais profundos.

Consideramos a identidade e subjetividade para trabalhar como categorias a partir do contexto em que são integrantes "constituidoras" na formação de valores no ciberespaço, nas salas de chats. Pois identificamos que o instrumento "hipertexto" se faz presente permeado de simbolismo e significado.

Os participantes da rede inscrevem nos hipertextos suas identidades a partir do momento em que tecem a seleção, a articulação e a reapropriação de novos pensamentos nas áreas dos sentidos. A construção da identidade é fundamental para a da subjetividade. $\mathrm{O}$ indivíduo necessita de bases, às quais possa recorrer quando preciso, para expor-se a "internalização" das regras de convívio social e a partir daí constituir a subjetividade. Abordamos as duas dimensões na formação do ser humano por entender que as duas têm bases de formação advindas do mesmo contexto - as experiências tecidas durante sua vida-, porém são conceitos diferenciados. Quando falamos de identidade, nos referimos àquilo que é próprio, particular e que somente o indivíduo poderá vivenciar consigo mesmo a partir da base em que foi se formando. A subjetividade fala do local de onde esse sujeito se formou, também advém das relações internas do sujeito em construção constante com o meio, só que na dimensão social. Estabelece-se pelo vínculo com sua posição que assume dentro de um contexto social.

Esse mesmo jovem, que busca construir sua identidade a custo das perdas dos traços familiares e das gerações que o antecedeu, é

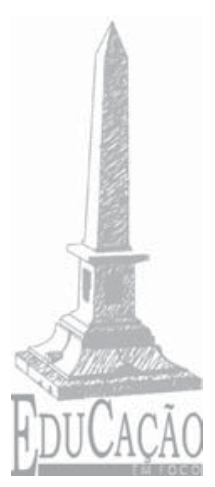

23 
o mesmo que realiza o seu espaço social. Seria difícil conceber o jovem dissociado do momento social e cultural. Por isso tentamos trabalhar as duas dimensões concomitantes, até mesmo por enxergar no ciberespaço um lócus diferenciado, pois construindo múltiplos caminhos de identidade através da vivencia social e cultural que perpassam esse lócus.

Do ponto de vista da identidade, temos como ideia básica que o ser humano é o tempo todo conjunto com a sociedade, e daí se desdobram papéis que assume e os desenvolve. Na fase do adolescente/ jovem existe uma "guerra interna e externa", em que o ponto central é a formação da identidade. Relembrando Erikson (1976), a identidade envolve mais do que o indivíduo e sua formação, comenta:

Eu denominei a maior crise da adolescência como sendo a crise da identidade. Ela ocorre naquela fase da vida em que cada jovem deve estabelecer, para si mesmo, certas perspectivas centrais e certa direção, alguma unidade de trabalho além dos vestígios de sua infância e das esperanças da sua antecipada idade adulta. O jovem deve descobrir alguma semelhança significativa entre o que ele vê em si mesmo e entre o que sua consciência afiada lhe diz que os outros julgam e esperam que ele seja (ERIKSON, 1976, p. 14).

Os padrões de desenvolvimento nos indivíduos assumem diferentes formas, como se fossem variações de um mesmo tema. Acontece assim a composição da identidade e da subjetividade, partindo do contexto de relações que o indivíduo irá tecer das experiências que realizar no cotidiano, desenvolvendo assim as próprias identidade e subjetividade. $\mathrm{O}$ adolescente/ jovem está situado na fase entre infância e fase adulta, carregando os traços dos dois períodos; o próprio passado e as falhas das gerações que vieram à sua frente.

Se os próprios jovens estão se enxergando dessa forma, alguma coisa está contribuindo para tal comportamento. Partindo das questões levantadas nas salas de chats, conseguimos perceber que os 
jovens transitam com facilidade e segurança nos aparatos tecnológicos, mas não é somente essa questão, notamos também a modificação da linguagem, do tratamento emocional entre eles. Observamos que alguns comportamentos que a gerações atrás não era permitido, os jovens hoje lidam com naturalidade. Por exemplo, o falar palavrões, cada um que em outros tempos seria um escândalo em locais públicos ou mesmo dentro de casa. Em outros tempos diriam nossos pais: - Falta de respeito! Hoje dizem os jovens: - Quem não fala! Hi!!!!!

Esses comportamentos e outros observados nas salas de chat e nas respostas dos questionários desenham um novo modo de construção da subjetividade e também influenciam na identidade que está em formação.

Quando identificam os amigos como o centro de suas atividades, os jovens (não adolescentes) demonstram que para realizar esse movimento de construção tanto da identidade como da subjetividade necessitam da legitimação do outro. Essa legitimação parece passar pelas vias da amizade enquanto: segurança, as mesmas gírias, as mesmas roupas, os mesmos filmes, as mesmas músicas, o esporte do momento, até mesmo os jogos veiculados na internet e chats. A partir da sociologia da juventude compreendemos que os jovens se organizam em grupos com identidades grupais definidas e diversas. Esse movimento é característico nas salas de chat. Por exemplo: os surfistas conversam em "dialeto surfes", os outros jovens que estiverem na sala que acompanhem ou não. Não interessa aos demais participantes na sala, eles desenvolvem a conversa em grupo fechado e ora se referem aos demais participantes para traçar uma brincadeira com alguém, "zoar" ou tecer comentários interessantes. Não há um único caminho, há sim múltiplas ideias que compõem um movimento dentro de alguns comportamentos constantes. Esse movimento é quase sempre o mesmo, o que pode significar a formação de um traço em comum entre os jovens tanto para constituir a identidade como para a subjetividade, dependendo do nível em que está sendo relacionado.

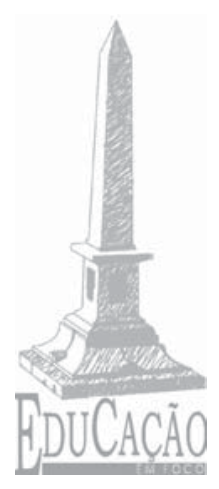

25 
A construção da subjetividade passa pela representação mental que organiza e compõe os objetos internos, tendo estes relações entre e com o mundo externo. Cada objeto interno forma-se pelo vínculo com a realidade externa, podemos dizer, a vivência diária de cada sujeito, podendo ter um caráter real ou não. Assim, as experiências vão sendo internalizadas pela soma desses fatores. Os papéis que os jovens representam estão presentes pelas relações sociais, conscientes ou inconscientes, que vivenciam em variadas situações. Assim, criam máscaras que pensamos ser eles mesmos. Essa vivência é constantemente experimentada nas salas de chat a partir do momento em que esses jovens criam estereotipo para si próprios e para os outros. Nesse momento se entende que a identidade está implicada nesse movimento, pois está sendo posta à prova, a todo o momento, por outros participantes nas salas de chat. Donde a construção da identidade será mais um componente a auxiliar na construção da subjetividade, e ambas estão sendo testadas nos chats pelos jovens.

Nas salas de chats verificamos que os jovens trocam suas identidades seja para "zoar", "mostrar aquilo que não é" ou "experimentar personalidades diferentes da sua". O que demonstra que tanto a autoimagem como a imagem social está em constante relação de aprendizagem e construção. Quando o próprio sujeito não tem consciência de que é a sua realidade que está sendo apresentada, configurando os "aspectos teatrais da vida cotidiana" (GOFFMAN, 1985), juntando a isso o receio de não ser aceito pelo grupo social, o indivíduo tende a representar um eu mais passível de aceitação, evitando uma atitude negativa ou hostil de um determinado grupo. Caracteriza-se então, nas salas de chats, a vivencia dessas máscaras que criam para evitar situações constrangedoras ou uma exposição excessiva de seu verdadeiro eu. E assim poder sentir-se legitimado, correspondendo aos seus anseios da construção da própria identidade.

Outra perspectiva é vivenciada nas salas de chats, o espaço do não-lugar, ou seja, o lugar em que se caracteriza por mera passa- 
gem e não por lugar de referencia. Os "não-lugares" ${ }^{5}$ dão margem ao surgimento do sujeito fractal, ou seja, um "Zapeador" ${ }^{\text {" }}$ de espaços. Esse sujeito caracteriza-se por estar desprovido de comprometimento com algum espaço referencial, possui uma identidade que é somente fluxo e deleita-se no intercâmbio de possibilidades que vivencia. Além disso, carece de encontros, pois vive da descontinuidade e da fragmentação, dentre outros conceitos que estão revestindo, hoje a subjetividade contemporânea. Essa visão de Rondini (1999) amplia a visão que se tem dos jovens enquanto navegadores das salas de chats no momento em que estão em várias salas ao mesmo tempo ou conversando com várias pessoas ao mesmo tempo, o que se assemelha também às características da identidade dos jovens na sociedade da informação. O contexto da sociedade pós-moderna parece estar auxiliando na formação desses indivíduos e sujeitos, se analisarmos do ponto de vista da maneira como os jovens se relacionam nas salas de chat. Observamos que no comportamento do "zoar" a caracterização do "descompromisso" com o que está sendo não somente veiculado como construído enquanto representação de si mesmo (do interno) e do que está posto externamente. Na fala de Rondini (1999) “Os ambientes virtuais ganham aqui, da perspectiva de quem se detém na discussão do sujeito e seus rastros de identidade, importância maximizada". Lemos (2001) traz a seguinte ideia:

Ao se conectar ao ciberespaço é dada a passagem da modernidade (onde o espaço é esculpido pelo tempo) à pós-modernidade (onde o tempo aniquila o espaço); de um sujeito uno, autônomo e isolado referendado na prática que se auto-institui do social - ao coletivo digital, dispersivo mas interconectado. A diferença, agora, é

\footnotetext{
${ }^{5}$ A partir do pensamento de Walter Benjamin se pode dizer que, "[...] com o risco de toda liberdade de figuração, que o advento das redes comunicacionais trazem, o continente natural e urbano perdeu a dimensão caracterizada pelo hic et nunc, o aqui e agora, que lhe conferia o caráter de coisa única no tempo e no espaço, com isso, lhe garantia a autenticidade e a autoridade histórica como original" (BENJAMIN, 1981 apud TRIVINHO, 1999).

${ }^{6}$ De acordo com Rondini (1999), esse sujeito é desprovido de referenciais, ou seja, carece de territorializar-se.
}

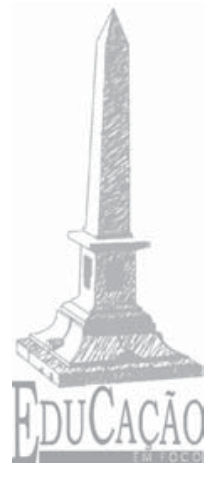


que ao sujeito é possibilitada enunciações rizomáticas de sentido, agenciamentos; construtos modelizantes não estabelecidos ou dados de antemão. A dispersão e a alta volatividade dos fluxos, que pode ser lida como superficialidade imanente desta contemporaneidade, também pode ser vista como maiores possibilidades de agenciamentos para tais sujeitos, porquanto que funcionalizem um processo comunicativo criativamente inovador (LEMOS, 2001, p. 01).

E instiga a questão: até que ponto esse espaço contribui na formação da identidade juvenil? Há ainda um campo aberto de investigação. De um lado ou de outro, tanto falando de identidade como de subjetividade, entendemos que o ciberespaço está mudando essas formas de conceber "territorializadas" e complexificando ainda mais as vias de compreensão desses conceitos. Os jovens dispostos nesses campos de interatividade constante tendem a redesenharem novos comportamentos. Somente a vivência e a constante busca pelo estudo desse fenômeno poderá nos auxiliar a compreender, de forma relacional, esses movimentos que vêm sendo traçados dia a dia tanto para o indivíduo como para o sujeito e os espaços que contribuem em sua educação formal.

É no ciberespaço, com a ferramenta hipertexto que tudo acontece, ou seja, que os jovens navegam nos chats. A interação nasce, brota, flui nesse contexto!

A chegada da sociedade da informação organizou novas formas de comunicação. Quando se "abre a porta" da internet lá está "ele", o novo meio de escrever e se comunicar - "o hipertexto". Esse novo jeito de se comunicar faz a passagem da oralidade para a escrita através da máquina - o computador. Além disso, se reveste de designs ao texto que o torna interativo, receptivo de todas as escritas e leituras do mundo, pois acontece no ciberespaço. Nesse hipertexto estão presentes "todos" aqueles que estão conectados, participando de um gigantesco texto de proporções infinitas devido à sua característica de continuidade por milhares de pensamentos que interagem, 
escrevem e reescrevem nas telas dos computadores.

Encontramos com facilidade as configurações do tipo de linguagem que os jovens utilizam nessas salas. As funções da linguagem nesse espaço são essenciais para comunicação entre eles, porém há ao mesmo tempo a construção/interação desses adolescentes/jovens construindo novos signos linguísticos que derivam da abreviação de palavras e criam assim significados para novos códigos.

O estudo do hipertexto pode nos direcionar a diversos caminhos, se entendido como espaço amplo de infinitas experiências e se o tomarmos como uma espécie de metáfora válida para análises de dimensões da realidade. Ramal (2002) comenta que restringir o campo de estudo no hipertexto significa restringir o âmbito das perspectivas de análises no ciberespaço. Dentro desse enfoque, interessanos estudar o hipertexto como lócus de mediação da significação, produção e reprodução e também a recepção de mensagens ideológicas que contribuam ou não para a formação dos sujeitos. Se assim concebido, concebe mudanças cognitivas de modo pessoal e social.

A partir do momento em que a forma de construção do hipertexto no ciberespaço se presta então a causar e sofrer influências tanto em sua organização quanto nos modos de expressão dos contextos em que estão sendo construídos. É interessante observar que mesmo que um hipertexto parta de um contexto definido, ele tenderá inevitavelmente, a partir de sua fonte, a pertencer ao universo de redefinição desse contexto e também do texto. Para Ramal, o hipertexto é a forma de leitura e escrita que mais se aproxima de nosso esquema mental, pois é assim que pensamos - igual a um hipertexto:

[...] sem limites para a imaginação a cada novo sentido dado a uma palavra, também navegamos nas múltiplas vias que o novo texto nos abre, não mais em paginas, mas em dimensões superpostas que se interpenetram e que podemos compor e recompor a cada leitura (RAMAL, 2002, p. 84).

Para Lèvy "hipertexto, a hipermídia ou a multimídia interativa percorrem um processo já antigo de artificialização da leitura"

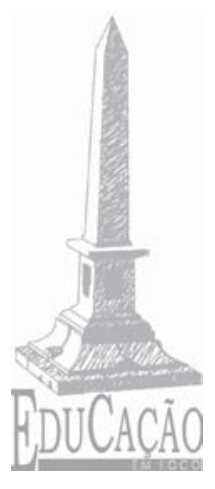


(LÈVY, 2002, p. 156). Podemos dizer que o hipertexto seria um texto em âmbito ampliado comparado às noções de texto, indo além dele. No hipertexto encontramos diversos assuntos que vão sendo associados a outros variados, conforme o interesse do leitor/escritor. Dessa forma, ele rompe com a ideia de linearidade e aproximase da rede. As páginas da internet são verdadeiros celeiros de produtores de textos, pois em cada espaço desse "o percurso textual é tecido de maneira original e única pelo leitor" (RAMAL, 2002, p. 85). Se para ler devemos selecionar, esquematizar, construir uma rede de remissões internas ao texto, deve-se associar a outros, integrar com palavras e imagens que formam uma memória pessoal em permanente reconstrução, então os dispositivos hipertextuais constituem uma espécie de reificação, de exteriorização dos processos de leitura. Perceber a diferença entre o sistema que existia estabilizado nas páginas dos livros e dos jornais e o sistema que se inventa hoje sobre as relações digitais nos leva a elucidar a presença das técnicas, que ao longo da história aperfeiçoou e hoje introduz a digitalização e a visualização como principais instrumentos da construção do texto. Não assistimos mais ao leitor que segue as instruções da leitura e se desloca no texto, mas sim a um texto móvel, "caleidoscópio que apresenta suas facetas, gira, torna e retorna à vontade diante do leitor" (RAMAL, 2002, p. 90). A escrita e a leitura mudam seus papéis. O próprio escritor se torna leitor e vice-versa numa dimensão de participação na estrutura do hipertexto, corroborando continuamente para costurar os possíveis sentidos em constante deslocamento.

A partir do hipertexto, toda leitura é uma escritura potencial. Mas sobretudo os dispositivos hipertextuais e as redes digitais desterritorializaram o texto. Eles fizeram emergir um texto sem fronteiras próprias, sem interioridade definível. Existe agora o texto, como se diz da água ou da areia. $\mathrm{O}$ texto é colocado em movimento, tomado em um fluxo, vetorizado, metamórfico. Está assim mais próximo do movimento mesmo 
do pensamento, ou da imagem que nós dele fazemos hoje (RAMAL, 2002).

É nessa dimensão que as conversas nas salas de chat se tornam textos constantemente "costurados" e "recosturados". As conversas se passam sobre os mais variados assuntos que vão sendo direcionados conforme a interação dos escritores como também dos leitores que são escritores e vice-versa. O entrecruzamento das ideias se estende a quem participa da conversa de forma reservada ou aberta no grupo. Todos em acesso a tudo que se passa na página principal, podendo intervir da maneira que desejar construir sua ideia e a do outro.

Há a presença de uma mobilidade textual e, digamos assim, de presença nas "costuras" das conversas. Os participantes podem intervir diretamente em todos os níveis de exploração da construção da conversa e com qualquer outro participante em particular ou com o grupo. Uma analogia possível seria assemelhar a estrutura construída de texto nas salas de chat com as "rodinhas de conversas entre jovens", porém há uma diferença fundamental, é a condução do texto no que tange à presença constante da virtualidade, do comprometimento ou não com o que se diz e escreve devido à ausência da presença do outro que limite o espaço. Nos grupos presenciais, se ocorrem momentos em que não gostamos de participar da conversa, podemos nos retirar, o arsenal físico ajuda a dizer o não. Nas salas de chats, percebemos que o não entre jovens pode significar mais "zoação" e maior interação até que se esgote a brincadeira. E durante esse percurso várias emoções são construídas, vividas com intensidade como se fossem presenciais. Há momentos em que a fala expressa felicidade ou raiva, carinho e afeição, exclusão e descaso. Essas construções estão no hipertexto de forma latente. As questões vão justamente refletir sobre a interferência de quem participa dessa construção hipertextual na construção e/ou modificações de ideias já concebidas ou mesmo aquelas que estão em construção.

Partindo do princípio que os jovens encontram-se numa fase da

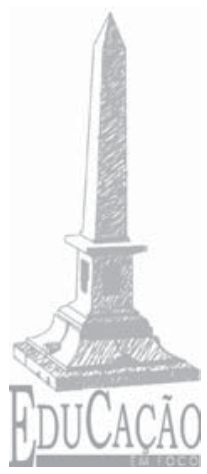


vida em que se questionam para selecionar e identificarem seus conceitos mais íntimos de identidade, o hipertexto deve possibilitar a intromissão em diversos campos dessa construção identitária. Essa nossa questão obteve por parte dos jovens uma mostra da negação desse movimento. Os jovens dizem em sua maioria que não mudam de ideia, que não estão dispostos a isso só porque estão lhe dizendo algo. Mas não se pode deixar de destacar que as relações construídas nesse espaço passam por momentos de significação e ressignificação de muitas ideias, o que inevitavelmente constrói de novos signos através da "desterritorialização" dos sentidos. No hipertexto os sentidos são múltiplos, seria praticamente impossível pensar em termos de "terminalidade" das ideias propostas nesse espaço. Isso também não implica dizer que todos os sujeitos expostos a essa experiência mudarão seus conceitos pessoais. Porém, é um ambiente que torna frágil os conceitos e propõe outras significações que podem ser interessantes ou não. E participar desse movimento implica também se apropriar da experimentação de "desterritorialização" das próprias ideias. A partir do momento em que nos relacionamos com outrem, já se estabelece uma relação de interação, e em toda relação desse nível estamos expostos a devires inesperados.

Outro dado importante é que percebemos que a maioria dos jovens que conversam nas salas de chats já se conhecem, e o contato com a própria turma presencial já determinou as regras do grupo a qual pertencem. Isso facilita para o jovem a questão da intervenção direta em seus conceitos pessoais. Porém, identificamos diversos casos, e até casos muito sérios, de adolescentes/jovens que em salas de chats se envolveram com pessoas, que causaram danos pessoais a esses jovens. São muitos os registros desses comportamentos. E para preservar sua identidade nos chats muitos jovens mudam suas identidades pessoais, resguardando-se dos perigos desse mega-hipertexto. Dizem mudar em todos os aspectos: residência, financeiro, aparência, idade, jeito de ser. E o fazem para: "manter o anonimato", " para não revelar a verdadeira iden- 
tidade", "vai depender da situação", "para não saberem quem sou", entre outros. Acontece também do jovem não querer que o amigo o descubra o que torna uma brincadeira ou uma conquista sensual no caso de namoros.

É interessante perceber que esse hipertexto também possibilita aos jovens testarem suas próprias concepções quando permite que se mostrem como não são. Essa situação passa por dois momentos: o momento do fingir ser quem não é para vivenciar uma condição diferente de personalidade e assim se testar e perceber suas características, ou seja, brincar com a própria personalidade; e em outro momento de realmente manter o comportamento de esconder algo, o que poderia ser induzido a desvios de personalidade. Esse movimento também implica na formação cultural. Lèvy comenta:

Eles desterritorializam o estoque de signos já disponíveis. Nada de espantoso nisto, uma vez que os novos suportes interativos saíram dos laboratórios e têm existência social efetiva há menos de dez anos. Dez anos! Quase nada em relação à escala de evolução cultural, muito menos tempo do que foi necessário a uma civilização para inventar uma escritura nova e remanejar, de um só golpe, seu dispositivo de comunicação, de produção e de transmissão de conhecimentos. No entanto, temos já sob os olhos, nos dois extremos da hierarquia cultural, as premissas da nova escritura (LEVY, 2002, p. 04).

O surgimento de um novo modelo de escrita que implica diretamente na formação cultural, que não podemos perder de vista enquanto referencial que reorganiza o contexto em que se compõe e é composto pelos participantes desse hipertexto.

Observamos que no hipertexto se fará presente o conceito de "polissemia", desenvolvido por Orlandi (1988), como processo que funda a linguagem e direciona a possibilidade da multiplicidade de sentidos diferentes, o que ocorre o tempo todo nas salas de chats. E Bahktin (1981) considera:

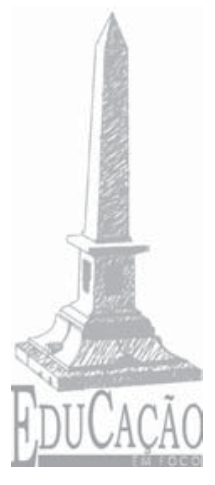


Os signos só podem aparecer em um terreno interindividual. Ainda assim, tratase de um terreno que não pode ser chamado de natural no sentido usual da palavra: não basta colocar face à face dois homo sapiens quaisquer para que os signos se constituam. E fundamental que esses dois indivíduos estejam socialmente organizados, que formam um grupo (uma unidade social): só assim um sistema de signos pode constituir-se (BAHKTIN, 1981, p. 35).

Implica dizer que essa concepção de linguagem vem ao encontro dos pensamentos de Lèvy (2002), nos demonstrando que o hipertexto irá, de uma forma ou de outra, propiciar esses encontros da produção subjetiva da linguagem configurando signos, em uma dimensão polissêmica, com a cultura em contextos diferentes e em constante modificação nas sociedades da informação e as formas de construção da aprendizagem.

Nesse sentido, os livros são ambientes criados por autores, editores, projetistas gráficos, desenhistas e até pelas pessoas que nos recomendam sua leitura. Mas o grande ambiente, claro, é criado pelo leitor. E os chats também não são ambientes criados por terceiros, com seus programas, softwares em determinados modelos que são postos para a distração dos que os acessam (lêem) e viajam na imaginação imersa nas interações que estabelecem com o outro. No caso do livro, digamos que é estático, porque a interação acontece na dimensão do leitor consigo mesmo, imerso na viagem criada pelo autor.

No chat o autor pode ser considerado não somente aquele que detém o programa do chat e o disponibiliza, como também o autor pode ser quem estiver criando a conversa no momento da interação com o outro na outra ponta da linha de conexão. Os desenhos, os gráficos, as imagens ficam por conta daqueles que desenharam o disign do chat, mas além desses, a criação do diálogo dá vida e movimento aos desenhos da forma que bem se deseje. É o que Lèvy (2002) nos demonstra com a questão de configurar a ideia que se 
deseja, não se podendo pretender domínio sobre o mega hipertexto que está sendo construído a partir da rede de informação via computadores. Em relação a essa rede, precisamos pensar e refletir sobre seu uso para que seja produtiva e crie ecologias cognitivas. Se assim o pensarmos, não poderia ser este mesmo ambiente - chat - um local de participação da construção dessa ecologia cognitiva?

Bem, os jovens têm vontade, mas ao mesmo tempo não têm orientação para tal intuito, pois há também um contexto de concepção do chat que é o de "passar o tempo" e "zoar", entre os jovens. E concluímos a partir de uma ideia de Lèvy (2002);

Pedagogos estudam as possibilidades de aprendizagem nesses locais, há programas de aprendizagem virtual elaborados pelos próprios jovens nas escolas. A criatividade se faz presente e a ferramenta favorável. O que devemos questionar e continuar pesquisando no ciberespaço das salas de chats se faz pelo próprio modelo de interação, no que ele propicia de construção subjetiva que realmente seja fator de consolidação aos valores, formação cidadã e ao crescimento coletivo da aprendizagem.

Não basta pensar a integração ou interação de ambientes virtuais. Não basta somente criticar ou simplesmente os reconhecer como espaços de desvirtualidade axiológica. Vários estudiosos enfatizam essa questão dos assédios e perigos do encontro virtual ou da mistificação da linguagem para abusos das mais diversas naturezas.

A questão dos valores não está posta somente em doenças psicológicas, está nas formas de relacionamento por vezes desenhadas na constituição social, no tecido do cotidiano, nas amarras das comunicações de massa. Essas precisam ser constantemente questionadas e discutidas com esses jovens aprendizes, que precisam refletir sobre o uso da virtualidade como objeto de ser e estar no mundo midiatizado e globalizado.

Valores estão na agenda de qualquer indivíduo e sujeito coletivo. Valores são fundamentos inegociáveis, são o bem que o outro pode retirar se permitido. Para tal, é necessário que as aprendizagens sobre valores perpassem a vida de cada sujeito na sua

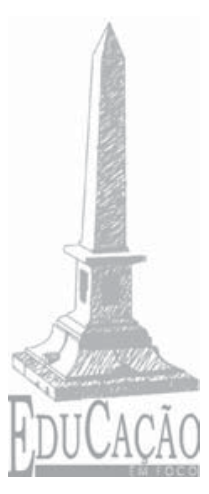

35 
integralidade. E aqui a subjetividade fundamental para a compreensão da vida em comunidade e ainda em propriedade única e intransferível de cada pessoa.

Dessa forma, conseguimos enxergar as propostas de salas de chats como possíveis ambientes de aprendizagem. É imprescindível que as pesquisas sejam ampliadas no sentido de estruturar essa ideia e contar com as falas dos jovens que estão navegando nesse espaço.

É preciso ainda considerar que a escola, na sua finalidade de sistematizar e operacionalizar a educação, esteja comprometida com as questões dos valores quando estrutura sua proposta pedagógica. Nisso a observação da dimensão educativa e da formação da subjetividade é extremamente relevante e valorativa, pois estão contidas experiências sociais e relações interpessoais que são desenvolvidas na escola.

A vivência dos valores corresponde a uma objetivação da experiência social e representa o fato em si, as aspirações e interesses vinculados ao imaginário que dele os jovens fazem. Se daí as construções subjetivas forem pensadas, podemos entender que as relações nos chats ou em qualquer outro espaço virtual estão presentes. Portanto, os dados encontrados nesta pesquisa contribuem para a compreensão do delineamento do imaginário do jovem não somente sobre o espaço virtual, mas sobre o uso do mesmo na escola.

Tendências, hoje, apontam ensaiar inferências educacionais que contribuam para a abordagem de propostas de aprendizagem com teor significativo, incluindo os espaços virtuais como experiências vivas de relações e subjetivação para que se desdobre em valores coletivos e auxiliem na etapa essencial do desenvolvimento humano - a juventude. 


\section{Referências}

ANTUNES, M. A. D. Descobrir e trabalhar valores do jovem na escola. Rio de Janeiro. 136 f. Tese (Mestrado em Educação) - Faculdade de Educação, Universidade do Estado do Rio de Janeiro, 1999.

CHAUÍ, M. Convite à filosofia. São Paulo: Ática, 1999. . DEBATES SOCIOLOGIA. Sobre Comunidade. N. 203, São Paulo: Editora Perspectiva, 1987.

DÍAS-AGUADO, M. J. Escuela y tolerancia.Madrid: Pirámide. 1996.

ERIKSON, E. H. Identidade juventude e crise. Tradução de Álvaro Cabral. Rio de Janeiro: Zahar Editores, 1976.

FUGLÉWICZ, M. Ciberética. São Paulo: Editora Loyola, 2001.

GOFFMAN, E. A representação do eu na vida cotidiana. Tradução de Maria Célia Santos Raposo. Petrpolis: Vozes, 1985.

GRINSPUN, M.P.S. Z. Relatório da pesquisa "os valores dos jovens no contexto atual". Rio de Janeiro: UERJ, 2002.

HENSSEN, J. Filosofia dos valores. Tradução de L. Cabral de Moncada. 5. ed. Coimbra: Armênio Amado Editor Sucessor, 1980. (Coleção Stvdium - temas filosóficos, jurídicos e sociais)

LEMOS, A. Tecnologia e vida social na cultura contemporânea. Site de pesquisa: Centro de estudos e pesquisa em cibercultura.

Disponível em: <http:/ / www. facom.ufba.Br / ciberpesquisa / txt_and3.htm>. Acesso em 2001.

MAFESOLLI, M. O tempo das tribos: o declínio do individualismo nas sociedades de massa. Rio de Janeiro: Forense Universitária, 2000.

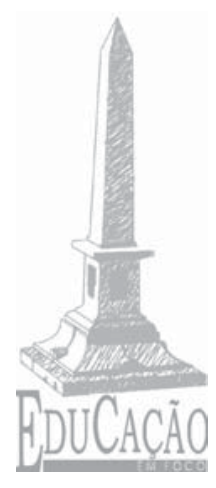

37 
PIAGET, J. O desenvolvimento moral da idade evolutiva. São Paulo: Loyola, 1975.

PADILHA, H. Moral. Rio de Janeiro: Linha Mestra Editora, 1999. (Coleção conversas com a escola)

RAMAL, A. C. Educação na cybercultura: hipertextualidade, leitura, escrita e aprendizagem. Porto Alegre: Artmed, 2002.

RONDINI, E. T. Cyberspace: crítica da nova comunicação. Tese (Doutorado em Comunicação) - Escola de Comunicação e Artes, Universidade de São Paulo, 1999.

SCHELER, M. Da reviravolta dos valores: ensaios e artigos. Tradução de Marco Antônio de Santos Casa Nova. Petrópolis: Vozes, 1994. (Coleção pensamento humano).

STOCKINGER, G. Sistemas informados - Teoria de comunicação para um mundo em movimento. Conferência durante concurso para professor titular em Teoria da Comunicação, Faculdade de Comunicação - Facom, Universidade Federal da Bahia 1999. (informação oral)

VIGOTSKI, L. S. Psicologia pedagógica. São Paulo: Martins Fontes, 2001. 


\title{
Young and subjetctive culture: identity and values in hipertextuality interact
}

\begin{abstract}
The research presents the analysis of the thesis "The young and the world virtu @ 1: the antics of the values in ch @ TSDA internet" are intended to identify values constructed by young people in cyber communication and their implications for individual and collective identity construction, explores concepts conceptual about the youth category, from the elaborate knowledge in communication relations experienced in cyberspace. Explore relationships with school learning and informal chat rooms. Qualitative approach, with descriptive and exploratory research, consisting of multiple instruments with techniques ranging from informal to formal questionnaires of chat rooms. The analysis and interpretation of data guided by the analytical method and dialectic, allowing constant formulating hypotheses. The theoretical intersperses clarifying aspects of sociology and psychology of youth, axiology of values and meaning/ significance of technology. Cyberspace resignifies spaces of teaching and learning in multiple ways that the subject today is composed/ constructed.
\end{abstract}

Keywords: Youth; values; subjectivity; identity; cyberculture.

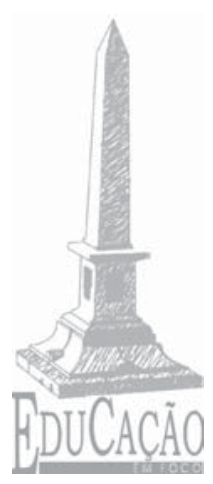

39

Ano 12 - n. 14 - dezembro 2009 - p. 13-39 